\title{
Speed Model of Electronically Controlled Diesel Engine Based on Sliding Mode Control
}

\author{
Yi Xiaobing \\ Hongshan three road 101, huangpu district, guangzhou,china \\ Guangzhou Maritime University, Marine Engineering, Guangdong Guangzhou 510725
}

Key word: Speed Model, Sliding Mode control, Simulation

Abstract:For the speed control of diesel engine, this research obtained data on a variety of key indicators by testing electronically control diesel engine in practice. Based on the data, we analyzed the impact of fuel injection quantity on speed control and its applicability to the variable structure system with sliding modes. Through data fitting in Matlab, the present article established the nonlinear relationship with the fuel injection quantity as the controlling variable and the speed as the controlled variable, and thus obtained a simulation model with correlations between fuel injection quantity and speed.

\section{Analyzing Nonlinear Speed Regulation}

Considering the dynamic characteristics of diesel engine, its speed change is determined by the difference between the value of output torque $M_{e}$ and the value of load torque $M_{l}$; according to the d'Alembert's principle ${ }^{[1]}$, its basic equation of motion is:

$$
\begin{gathered}
J \frac{d \omega}{d t}=M_{e}-M_{l}, \\
\text { Wherein } M_{e}=M_{i}-M_{f}
\end{gathered}
$$

Wherein $\mathrm{J}$ denotes the total equivalent moment of inertia of both the diesel and the load, and $M_{l}, M_{f}, M_{i}$ are all complex functions of multi-variables.

In terms of the turbocharged diesel engine, when the speed change is under control, the response time of fuel injection is much shorter than that of the gas supply. Because of turbocharger lag effects, the increase of the fuel injection quantity is faster than that of the turbocharger pressure and thus the diesel is in incomplete combustion and at low air-fuel ratio, which means that less air moves into the engine resulting in a low combustion efficiency ${ }^{[2]}$. In this case, the diesel engine performs poorly in dynamics, economy and emissions ${ }^{[3]}$.

Because of its robustness and good anti-interference capacity, Sliding Mode Control has been widely applied to both linear and nonlinear systems that feature uncertainties such as aircraft, ships and robots ${ }^{[4]}$. And the diesel speed control is just the typical problem of this type to be solved. 


\section{Sliding model control}

Most of the actual control issues are nonlinear, disturbing and uncertain. Hence, it is necessary to adopt a more theoretically optimized nonlinear feedback and transformation-based control system to achieve sound dynamics and thus obtain satisfactory control results ${ }^{[5]}$.

Provided there is a control system,

$$
\hat{x}=f(x, u, t), x \in R^{n}, u \in R^{m}, t \in R, t \in R
$$

The design of the switching function $s(x), s \in R^{m}$ is needed, and then the control function is solved ${ }^{[6]}$ :

$$
u=\left\{\begin{array}{l}
u^{+}(x), \quad s(x)>0 \\
u^{-}(x), \quad s(x)<0
\end{array} \text {, wherein } u^{+}(x) \neq u^{-}(x) .\right.
$$

\section{Fitting Polynomials of the Electronically Controlled Diesel Engine Speed Control}

The present study first established the mathematical models of both partial speed characteristics and of universal characteristics and then conducted a test ${ }^{[7]}$. Based on the test data, this study verified the mathematical models. The models incorporate mathematical descriptions of the main characteristics of the diesel engine. And after putting the two models to testing, a series of data was obtained: part of the data was employed in establishing the diesel engine model, and part was used in exploring the curves of the external, universal and partial characteristics $^{[8]}$. By employing the dynamometer, we further obtained the velocity of the diesel engine, the torque value and the fuel injection quantity $\left({ }^{q}\right)$. After fitting the coefficients of the mathematical equations in Matlab, we finally obtained an equation that takes the fuel injection quantity as the controlling variable and the diesel engine speed the controlled variable ${ }^{[9]}$.

Both the engine speed $n$ (rpm) and the cyclic fuel injection quantity $q$ (g) are measurable, and the engine torque $\mathrm{T}(\mathrm{Nm})$ can be obtained with the diesel hydraulic dynamometer beforehand $^{[10]}$.

The relationship among the speed, fuel injection quantity and torque of a certain type of diesel engine can be obtained by analyzing the fuel injection quantity and torque data at different speeds respectively. Due to space limitations, this article randomly took the data at the speed of $1000 \mathrm{r} / \mathrm{min}, 1200 \mathrm{r} / \mathrm{min}, 1400 \mathrm{r} / \mathrm{min}, 1600 \mathrm{r} / \mathrm{min}, 1800 \mathrm{r} / \mathrm{min}, 2000 \mathrm{r} / \mathrm{min}, 2200 \mathrm{r} / \mathrm{min}$ and 2400 r/min for analysis, and the results shown in Figure 1 and Figure 2. 


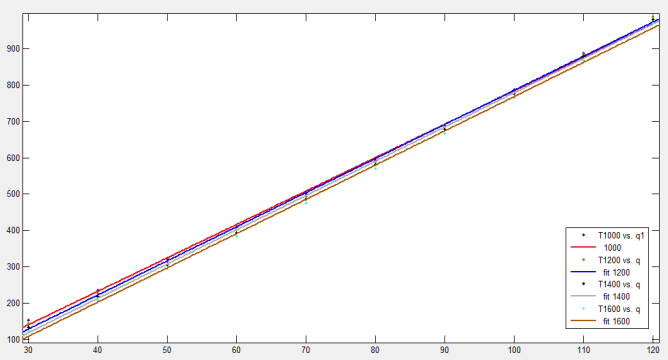

Figure $1 T-q$ Relationships When $n=1000 / 1200 / 1400 / 1600 \mathrm{r} / \mathrm{min}$

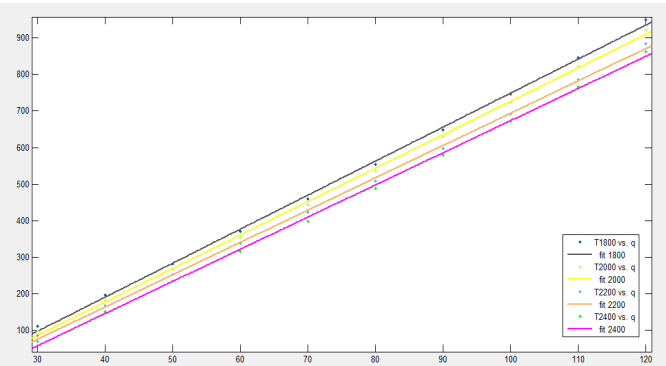

Figure $2 T-q$ Relationships When $n=$ $1800 / 2000 / 2200 / 2400 \mathrm{r} / \mathrm{min}$

Obviously, when the speed is fixed, the T-q relationship is linear. Therefore, the torque can be expressed as:

$$
T=a q+b
$$

Table 1 Data on the $T$ and $q$ Fitting

\begin{tabular}{|c|c|c|c|c|c|c|c|c|}
\hline $\mathrm{n}$ & $\begin{array}{c}1000 \mathrm{rp} \\
\mathrm{m}\end{array}$ & $\begin{array}{c}1200 \mathrm{rp} \\
\mathrm{m}\end{array}$ & $\begin{array}{c}\text { 1400rp } \\
\mathrm{m}\end{array}$ & $\begin{array}{c}\text { 1600rp } \\
\mathrm{m}\end{array}$ & $\begin{array}{c}\text { 1800rp } \\
\mathrm{m}\end{array}$ & $\begin{array}{c}\text { 2000rp } \\
\mathrm{m}\end{array}$ & $\begin{array}{c}\text { 2200rp } \\
\mathrm{m}\end{array}$ & $\begin{array}{c}\text { 2400rp } \\
\mathrm{m}\end{array}$ \\
\hline $\mathrm{a}$ & 9.19 & 9.38 & 9.43 & 9.42 & 9.30 & 9.14 & 8.83 & 8.83 \\
\hline $\mathrm{b}$ & -135.00 & 152.80 & -164.00 & 174.10 & 181.50 & 187.80 & 189.40 & 189.40 \\
\hline
\end{tabular}

$\mathrm{a}$ and $\mathrm{b}$ can be fitted to the polynomials of $n$ respectively, as shown in Figure 3 and Figure 4.

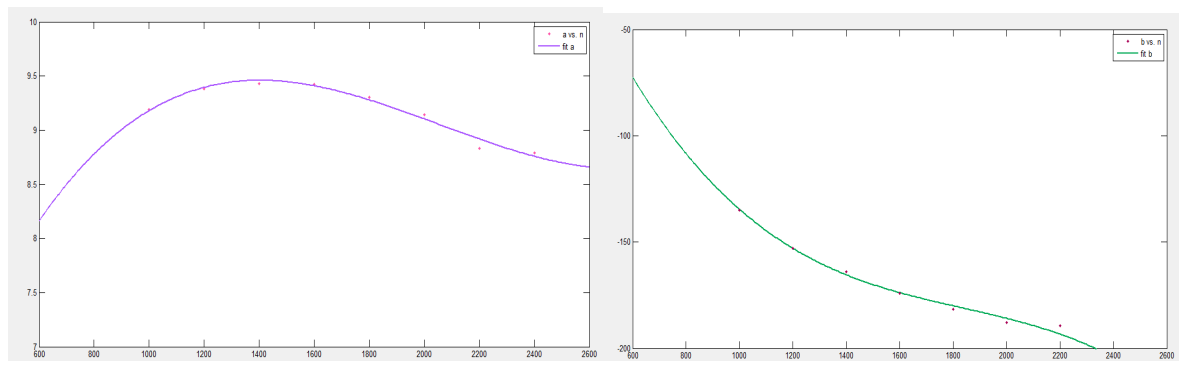

Figure 3 Polynomial Results of a Fitted to $n$ Figure 4 Polynomial Results of b Fitted to $n$

Then we can get $a=7.289 * 10^{-10} \mathrm{n}^{3}-4.499 * 10^{-6} n^{2}+0.008318 n+4.632$

$$
b=-3.886 * 10^{-8} n^{3}+0.000214 n^{2}-0.4213 n+111.6
$$

$$
\begin{aligned}
\frac{\pi J}{30} \frac{d n}{d t}=a q+b-M_{l} & =\left(7.289 * 10^{-10} \mathrm{n}^{3}-4.499 * 10^{-6} n^{2}+0.008318 n+4.632\right) q+ \\
& -3.886 * 10^{-8} n^{3}+0.000214 n^{2}-0.4213 n+111.6-M_{l}
\end{aligned}
$$

As there is a great difference between the cubic coefficient and the squared coefficient, the model can be approximately expressed as:

$$
\frac{\pi J}{30} \frac{d n}{d t}=\left(-4.499 * 10^{-6} n^{2}+0.008318 n+4.632\right) q+0.000214 n^{2}-0.4213 n+111.6-M_{l}(9)
$$


Take a certain type of electronically controlled diesel engine for example:

$\mathrm{J}=5.6, \frac{\pi J}{30}=0.58643$

$$
\begin{gathered}
\frac{d n}{d t}=\left(d_{1} n^{2}+d_{3} n+d_{5}\right) q+d_{2} n^{2}+d_{4} n+d_{6}-\frac{30}{\pi J} M_{l} \\
\text { Making } \frac{30}{\pi J} M_{l}=f\left(M_{l}\right), \\
d_{1}=-4.499, \quad d_{3}=0.008318, \quad d_{5}=4.632, \\
d_{2}=0.000214, \quad d_{4}=-0.4213, \quad d_{6}=111.6
\end{gathered}
$$

With the fitting method mentioned above, we obtained the differential equation that shows the typical complex nonlinear relationship between the diesel engine speed and the fuel injection quantity. Thus the engine speed can be effectively controlled by adopting the sliding mode control algorithms ${ }^{[11]}$.

\section{References:}

[1] Zhu Jian, Wu Jian. Numerical calculation and optimization of internal combustion engine working process [M]. Beijing: National Defence Industry Press, 1997

[2] Chen Chen. Research on performance simulation test method of diesel engine electronic speed governor [D]. Wuhan: Huazhong University of Science and Technology, 2001

[3] Zhu Meilin. Engine turbo [M]. Wuhan: Central China University of Science \& technology, 1999

[4] Munoz D, Sbarbaro D. An adaptive sliding-mode controller for discrete nonlinear systems.IEEE Transactions on Industrial Electronics, 2000, 47(3):574-581

[5] Utkin V. I. . Sliding mode and their application in VSSs, Moscow, 1978

[6] Itkin U. . Control systems of variable structure, John wiley \& Sons, 1976

[7] Zhang K Y,Su H Y, Zhang K Q,Chu J. Adaptive terminal sliding mode control for high order nonlinear dynamic systems.2003,4(1):58-63

[8] Ha Q P, Nguyen Q H, Rye D C, etal. Fuzzy sliding mode controller with application [ J ] . IEEE Transaction on Industrial Electronics, 2001, 49 (1): 38241.

[9] Lin S C,Chen Y. RBF network based sliding mode contol. IEEE International Conference on Systems,Man,and Cybernetics, 1994,1957-1961

[10] Parma G,Menezes B R,Braga A P, Costa M A.Sliding mode neural network control of an induction motor drive,International Journal of Adaptive Control and Signal Processing, 2003, 17(6): 501-508

[11] Li Yuhui. Design and research of electronic control system controller for medium pressure common rail diesel engine. Doctoral dissertation of Wuhan University of Technology, 2004 